\title{
TRANSPARENCIA, ACCESO A LA INFORMACIÓN TRIBUTARIA Y EL SECRETO FISCAL. DESAFÍOS EN MÉXICO
}

Víctor Hugo Hiram MAGALLANES MARTÍNEZ*

En un Estado democrático de derecho se busca que tanto autoridades como ciudadanos convivan en un ambiente de confianza y seguridad, de manera que a los poderes públicos se les permite y a la vez se les limita su actuación en beneficio de la sociedad, pero también se le impone al ciudadano la responsabilidad de adoptar un rol protagónico, a través de su participación proactiva, en la "cosa pública”, entendida ésta en su acepción más genérica al referirse a las actividades que despliega el ente de gobierno.

No es simplemente señalar la existencia de la obligación estatal de garantizar ciertas libertades, la responsabilidad del Estado va más allá, dado que lo que se pretende es que se encuentren al alcance del particular diversas herramientas que mejoren la relación Estado-ciudadano. La tarea de hacer transparente esta relación es complicada, y en el ámbito tributario existen grandes desafíos por emprender por parte de las autoridades, del ciudadano, del sector académico, y, en sí, de todos los operadores jurídicos.

En ese contexto, considero conveniente que existan textos que aporten ideas con el objeto de lograr un mayor entendimiento entre contribuyente y gobierno. El libro que se presenta es por sí un estudio serio y comprometido, que toca temas que cuestionan, preguntan y reflexionan sobre la actualidad de nuestra sociedad, lo que es loable para efectos de una adecuada nutrición cultural de todo lector.

Generalmente cuando se resume una obra se realiza un análisis descriptivo de su contenido, teniendo como base la propia relación de ideas que plasmó su autor; es decir, partir de lo general para aterrizar las con-

Licenciado en derecho; Juzgado Tercero de Distrito en el Estado de Morelos, biktor25@hotmail.com. 
Esta revista forma parte del acervo de la Biblioteca Jurídica Virtual del Instituto de Investigaciones Jurídicas de la UNAM

clusiones en la parte final. Sin embargo, considero que el texto nos brinda la oportunidad de comenzar de una manera distinta, comentando primero las reflexiones finales — que se plasman a manera de desafíos-, y después narrar la forma en que cada una de éstas se fueron concibiendo en el desarrollo de la obra.

Lo anterior porque, como fue mencionado por las propias autoras en el último capítulo, el orden analítico del texto permitió identificar y adelantar algunos desafíos en la materia, así como su complejidad y vertientes de la problemática jurídica y práctica fiscal. Como reflexiones finales nos compartieron las siguientes:

a) Profundizar y desarrollar comprensivamente el contenido doctrinal de la transparencia y acceso a la información tributaria.

b) Analizar los casos de excepción a la reserva fiscal; es decir, la apertura relativa del secreto, en la cual debe operar y bajo qué argumentos; igualmente, aplicar el control de proporcionalidad o juicio de ponderación que requiere para examinar el balance de los derechos en cuestión.

c) Trazar una armonización adecuada de las normas tributarias con la garantía constitucional del derecho de acceso de información y la protección de los datos personales.

Sobre el primer punto de reflexión en la obra se desarrollan una serie de conceptos y fundamentos clave, partiendo de la idea de que el derecho tributario en una democracia no puede omitir ni evadir los principios constitucionales y mucho menos ir en contra de ellos. Por ello es que - de inicio- se plantea la siguiente interrogante: ¿qué diferencia tiene la transparencia y el derecho de acceso a la información? Las autoras señalan que a diferencia de la transparencia, los derechos a la información y al acceso a la información sí son derechos fundamentales establecidos en la Constitución mexicana, y que la transparencia es un concepto de la teoría de la administración pública que se sitúa en un contexto neoliberal que propone reformas estructurales en la relación gobierno-ciudadano hacia una "nueva administración pública”.

Así, la transparencia es una obligación del Estado, que se cumple a través de políticas de información, comunicación, difusión, de testigos sociales, de reuniones abiertas, entre otras formas. En contraste, el derecho de acceso a la información es un derecho de los ciudadanos a exigir transparencia a sus gobernantes con información de interés público. 
De esta manera —nos afirman-, la transparencia y acceso a la información tiene sentido en el entorno de las contribuciones, toda vez que el derecho tributario es parte del derecho público, y sus acciones corren a cargo de la administración pública federal. Así, es que la información y datos derivados de la gestión tributaria deben ser valorados, en cuanto a su apertura y resguardo, desde el derecho público y sus bases garantistas constitucionales.

En ese contexto, también nos indican que la transparencia y acceso a la información tributaria opera en dos direcciones: de los contribuyentes hacia la autoridad hacendaria, y de ésta hacia los contribuyentes. La primera se confecciona sobre la obligación constitucional de los contribuyentes de otorgar pleno acceso a la autoridad sobre sus finanzas y aportaciones. La segunda es sobre la información que detentan las administraciones tributarias sobre los particulares, tanto de aquella que pueda ser de ayuda a los contribuyentes en el cumplimiento de sus obligaciones, pero también sobre el cumplimiento de las obligaciones de otros contribuyentes y del desempeño, decisiones, normas y resultados de las funciones de la propia autoridad.

Entonces, existe una responsabilidad compartida, en tanto los ciudadanos como sus representantes se dan a la tarea de analizar, criticar y revisar las consecuencias de su propia conducta, y procuran cogobernarse, que es justamente el acto donde se alberga el interés público. En torno a esta figura, nos señalan que no debe ser confundida con lo que interesa al público en términos de escándalos mediáticos, pues se habla de un concepto que requiere de una justificación de principios socialmente aceptados mediante la interpretación de la ley. Es decir, el autor trata de traducir la revolución social en criterios legales, que el perito debe definir de acuerdo con la doctrina y otras ciencias adicionales al derecho, incluyendo elementos y datos que le ayuden a probar el razonamiento. El concepto de interés público puede también ser visto como una condición y como la norma de evaluación que da sentido a la idea de los derechos y deberes políticos.

En la transparencia y acceso a la información tributaria, el interés público, traducido en el interés de la colectividad, se conduce como la base justificativa para abrir el escrutinio de los contribuyentes: datos de todos éstos, normas y acciones de la autoridad hacendaria, y cualquier información que pueda dignificar o contribuir al bienestar de la población. Además, la autoridad debe garantizar el derecho de acceso a la información de las personas y motivar explicativamente la excepción a la apertura.

De manera posterior a las reflexiones sintetizadas en los párrafos anteriores, las autoras nos exponen otros conceptos, como son los relativos al derecho a la intimidad y el de protección de datos personales. 
Esta revista forma parte del acervo de la Biblioteca Jurídica Virtual del Instituto de Investigaciones Jurídicas de la UNAM www.juridicas.unam. $m x$

DOI: http://dx.doi.org/10.22201/iij.25940082e.2017.3.10829

En cuanto al primero, cubre dos aspectos: el denominado estático-negativo, que implica que los demás quedan excluidos del conocimiento de la esfera individual, y el aspecto dinámico-positivo, que se configura como una nueva libertad personal, más como libertad positiva de ejercitar un derecho de control de los datos referidos a la persona que ha salido de la esfera privada para insertarse en un determinado archivo público o privado. Las manifestaciones del derecho a la intimidad (aspecto estático-negativo y dinámico-positivo) están presentes en la relación de la administración y el contribuyente.

En lo que atañe a la protección de datos personales, las autoras indican que es el sistema de principios, regulaciones y tratamiento, métodos y medios de recolección de datos que garantizan la recolección limitada, tratamiento y uso de los datos y la protección del interés de las personas.

En el capítulo segundo se traza un vínculo conceptual entre la doctrina del derecho de acceso a la información con el derecho tributario, en particular con la obligación de contribuir de los ciudadanos y los fines de recaudación de tributos de la autoridad. Por ello, las autoras definen el concepto de derecho de acceso a la información tributaria utilizando elementos de ambas doctrinas, y señalan que éste consiste en garantizar el derecho a la información de las personas y el reservar siempre información que podría dañar el interés público y los derechos de terceros.

Desde la perspectiva del deber constitucional de contribuir y del deber de informar a la autoridad fiscal, se señala que el primero debe protegerse y cumplirse, pero también genera derechos públicos subjetivos en favor de los contribuyentes, entre éstos cabe mencionar los que están relacionados con el derecho al acceso a la información tributaria. De tal manera que resulta consustancial al derecho tributario, el derecho de acceso a la información como principio de transparencia y de libertad individual, cuyo origen se localiza en el principio de certeza y seguridad jurídica. En lo que se refiere al segundo deber, se menciona que los datos que los contribuyentes están obligados a otorgar a la hacienda pública se pueden distinguir entre datos personales y datos con relevancia tributaria.

Es claro que estos conceptos brotaron en el desarrollo del texto para evidenciar el necesario contenido doctrinal a que hace referencia el primer desafío, pues como se afirma en la parte final de la obra, contemporaneizar dos vínculos entre los gobernados y los gobernantes es una tarea pendiente en la empresa de estudiar el acceso de información tributaria. Si bien tradicionalmente se entiende que el fisco informa al contribuyente a través de sus facultades de asistencia y orientación, sucede que la Ley Federal de Transparencia y Acceso a la Información Pública emprende nuevos canales 
para que, más allá de lo que por obligación o voluntariamente el Estado informa, se abra otra información directamente a petición del solicitante.

Por lo que se refiere a analizar los casos de excepción a la reserva fiscal y que es plasmado como un segundo reto, en el contenido de la obra se comienza con la idea de problematizar la obligación de la autoridad fiscal de garantizar el derecho de acceso a la información. Se nos dice que la garantía de acceso a la información tributaria es una obligación del Estado para evitar que los poderes amplios de la hacienda pública sean mal usados por los funcionarios y servidores, y se causen perjuicios a los contribuyentes y al erario; para tales efectos, el acceso se garantiza a través de: a) la política de transparencia proactiva, en aras de promover el cumplimiento del pago de impuestos y evitar el fraude; $b$ ) recibir y responder a solicitudes de acceso a la información pública, por medio de la fundamentación y motivación de la reserva de información; c) permitir acceso y garantizar la protección de los datos personales de los contribuyentes, y d) dar información oportuna y veraz sobre las consultas tributarias planteadas por los contribuyentes respecto a su situación legal. No obstante, también se señala que el derecho de acceso a la información encuentra límites mediante dos formas: la jurisprudencial y la legislación.

A lo largo del texto se nos expone que la información tributaria puede ser clasificada por el legislador como reservada confidencial, o incluso no clasificarla y permitir la máxima apertura sobre ésta. Aquí es donde cobra vital importancia la figura del secreto fiscal, pues representa una obligación para las autoridades fiscales, de guardar absoluta reserva de lo concerniente a las declaraciones y datos suministrados por los contribuyentes, esto es, no podrá evocarse la reserva por otra materia que la referida.

En ese orden de ideas, para las autoras debe destacarse que el Código Fiscal de la Federación, que data de la década de los ochenta, crea una cerrazón absoluta a priori de la información, ya que es claro que la información de relevancia tributaria y los datos personales no tienen la misma naturaleza ni se protegen igual. Para evidenciar esta afirmación, la autoras señalan que la primera información se integra de datos patrimoniales que el contribuyente entrega a la autoridad fiscal en el cumplimiento de sus obligaciones fiscales, y la segunda es información de las personas que se encuentra en posesión del Estado y que algunas leyes declaran como confidencial.

También se menciona que entre las características negativas del secreto fiscal es que, por un lado, se reserva la información de los contribuyentes que éstos entregan a la autoridad, pero además todos aquellos documentos administrativos de la autoridad que derivan de sus obligaciones y fines 
Esta revista forma parte del acervo de la Biblioteca Jurídica Virtual del Instituto de Investigaciones Jurídicas de la UNAM www.juridicas.unam.mx

DOI: http://dx.doi.org/10.22201/iij.25940082e.2017.3.10829

revistas.juridicas.unam. $\mathrm{mx}$

VÍCTOR HUGO HIRAM MAGALLANES MARTÍNEZ

de recaudación, incluyendo lineamientos y criterios de la ejecución de su función.

Incorporándonos ya en el capítulo tercero, en la obra se señala que la literatura del secreto fiscal en México es escasa y en ocasiones poco clara al identificar la materia y naturaleza de esta reserva. De hecho, hay una dificultad generalizada por justificar su existencia y definir sus límites y alcances, puesto que su conformación no parte de la voluntad del individuo, sino de la obligación tributaria que deriva del mandato legislativo.

Después de realizar diversas aproximaciones en torno al secreto fiscal (definición, su desarrollo en México y marco normativo) surge la siguiente interrogante: ¿cuál es el bien jurídico que se tutela?

En el texto se nos señala que para conocer la procedencia del interés del resguardo es necesario identificar cuál es el contenido del secreto fiscal, según su configuración jurídica, qué tipo de conocimiento resguarda este secreto. En principio, es claro que los datos que resguardan son aquellos suministrados por los contribuyentes, que son personas físicas y morales, o los que recaba la autoridad en el ejercicio de sus facultades de comprobación. Al final, son datos de personas relativos a su vida privada, sus valores, patrimonio, etcétera.

En términos prácticos, dentro de la arcana fiscal existen datos, tales como nombre, razón social, domicilio particular, declaraciones, gastos médicos, pensión alimenticia, clave de registro, representante legal, entre otros, de personas físicas y morales. Además de estos datos, se encuentran datos contables que se reflejan en la declaración de contribuciones, como la base imponible, deducciones, base liquidable, así como datos formales; por ejemplo, domicilio fiscal, el Registro Federal de Contribuyentes y la Clave Única de Registro de Población.

Ahora bien, en la obra se expone que la voluntad de crear el secreto fiscal es del titular de los datos (contribuyente), que en el pleno ejercicio de su libertad y en cumplimiento de su deber de informar al Estado, impone el carácter confidencial al otorgárselo a la autoridad fiscal; pero ¿qué pasa cuando la autoridad fiscal, en el ejercicio de sus funciones de recaudación, recoge o investiga datos sobre contribuyentes?, ¿sigue siendo la voluntad del sujeto de la información? En este supuesto existe un interés de la autoridad para garantizar el derecho fundamental de las personas a la vida privada, y una obligación constitucional y legal de proteger sus datos personales, el cual deriva de la finalidad para la que resguarda los datos.

Sin embargo, surgen dos problemas: primero, para el marco jurídico mexicano de la protección de datos personales sólo se consideran como tales los de las personas físicas y no las morales. Esto plantea un desafío 
inicial para definir el tipo de información que resguarda el secreto fiscal; segundo, que como régimen de datos personales vigente no existen subcategorías de respeto a la vida privada de las personas; esto es, toda información de una persona, ya sea su religión o su información económica, son igualmente consideradas como confidenciales.

Como se ve, dentro de la literatura, el bien protegido en los secretos jurídicos es quizá una de las partes más difíciles de delimitar, y la literatura no es unívoca, dado que el sigilo puede tener diferentes aplicaciones en contextos disímiles. En este caso, las autoras identifican dos tipos de resguardo de la información: a) la confidencialidad, que protege los datos personales que permitan identificar a una persona, y b) la reserva, que contiene los datos contables o de relevancia tributaria de los sujetos. Esta diferencia estriba en que los dos tipos de secretos obedecen a dos tipos de intereses y bienes jurídicos diferentes.

Por lo que hace al concepto de transparencia tributaria, explicada de manera detallada en el capítulo cuarto, se dice que ha sido tratada con más profundidad en la literatura de la economía y las finanzas que en la doctrina jurídica, y que, por la primera, el sentido de la transparencia fiscal se explica a partir de razones de: a) distribución equitativa de la riqueza; b) endeudamiento del Estado y recaudación, manejo de finanzas; c) facilitar trámites y pagos con relación a la inversión extranjera; $d$ ) combate al crimen, lavado de dinero e intercambio de información internacional, y e) crear estadísticas y estudios para lograr grandes cambios estructurales.

Pero también se precisa que la transparencia tributaria tiene sentido desde el punto de vista jurídico para el mejor cumplimiento de los contribuyentes con sus obligaciones fiscales, la verificación de las obligaciones de contribución y las facultades de comprobación, evitar fraudes y conflictos entre contribuyentes, la protección y garantías de los derechos de los contribuyentes y sus datos personales, la rendición de cuentas de las autoridades hacia los ciudadanos en el ejercicio de sus funciones de recaudación y como instrumento de cooperación internacional respecto a la atracción de capital, la elusión y evasión de contribuciones.

Para las autoras del libro, la transparencia tributaria implica apertura de información, normas, procedimientos y comportamientos entre gobiernos y sus diferentes niveles, y entre éstos y los ciudadanos. Lo que es claro en las definiciones estudiadas — y en lo que hay coincidencia - es que las reglas fiscales, que rigen el comportamiento de gobiernos y ciudadanos, deben proveer confianza; requieren ser lo suficientemente claras y sencillas para incentivar a su cumplimiento, y eficaces para que disminuyan la controversia y otorgar seguridad jurídica. Así, se señala que el secreto 
tributario debe estar permitido en regímenes democráticos por fines de interés público socialmente autorizados y jurídicamente justificados.

Con base en las aproximaciones anteriores es que, también en la parte final de la obra, las autoras plantean el segundo reto concerniente a la configuración del secreto fiscal, lo cual — sostienen — no es nada fácil y parte de la contrariedad, ya que entre los expertos de los ramos que se mezclan tampoco existe consenso, pues algunas corrientes doctrinales consideran que el secreto fiscal no protege derecho alguno, mientras que otras argumentan que la protección versa sobre el derecho a la intimidad, vinculada con la vida privada del contribuyente. En una tercera postura se cuestiona si en - realidad únicamente se protegen datos personales y, como tal, entonces no - cabría la protección de los datos de las personas morales.

Por ello, el reto es la realización de estudios crónicos en la doctrina y la jurisprudencia, que permitan discernir con claridad cuáles son los derechos fundamentales que se protegen o se excluyen del secreto tributario, para así saber en qué casos debe operar la apertura del sigilo.

A manera de propuesta se señala que vale la pena recordar ciertos supuestos que se han tomado para tratar el tema de la apertura fiscal. Primero, existe una heterogeneidad en el régimen fiscal y en el régimen del derecho de acceso a la información sobre la reserva, ya que tanto la reserva de los datos como la confidencialidad tienen consecuencias jurídicas distintas, responden a intereses diversos y desencadenan doctrinas diferentes; por ejemplo, el periodo de reserva varía, o la viabilidad de pruebas de interés público o de daño. Segundo, la confidencialidad en el régimen fiscal es absoluta, mientras que en el acceso de información es relativa, pues existen versiones públicas donde los datos pueden desagregarse para no hacer identificable a la persona física. Tercero, tanto abrir como reservar los datos tienen consecuencias positivas como negativas, por lo que se debe actuar de manera casuística, fundada y motivada en derecho.

Pero surge otra cuestión: ¿cuál sería el mejor canal para realizar dichas categorías o reclasificaciones? Ante esta pregunta se plantean dos posibilidades: que se realice ope legis; es decir, mediante mandamiento legislativo, en el que el legislador motive suficientemente esta reclasificación, o bien a través de la interpretación jurisdiccional, y que sea éste el que aplique el control de proporcionalidad de la medida empleada por el legislador; esto es, determinar si fue idónea la clasificación, necesaria y proporcional al fin que se persigue.

Finalmente, por lo que hace al tercer desafío, en la obra se plasma la necesidad de armonizar las normas tributarias con la garantía constitucional del derecho de acceso a la información y la protección de datos personales; 
para ello, las autoras parten de la premisa de que un Estado democrático es aquel sistema legal que sanciona y respalda los derechos y libertades del régimen democrático, y donde las instituciones implementan esos derechos y trabajan en la dirección de hacerlos efectivos. Es un Estado que funge como un ancla indispensable de los derechos de la ciudadanía.

En un contexto como éste, y para que las funciones del Estado, en efecto, garanticen los derechos y las libertades, se requiere que el sistema normativo que legitima al Estado democrático tenga coherencia con la garantía. Es así que un desafío más es la armonización de las normas, para que - ciertamente- en lo que toca al sistema fiscal, se conciba el balance justo entre el derecho de acceso a la información y su principio de la máxima apertura, el derecho a la vida privada de los contribuyentes, el interés público y tributario.

\section{BibLIOGRAFÍA DEL LIBRO RESEÑADO}

Luna Pla, Issa y Ríos Granados, Gabriela, 2010, Transparencia, acceso a la información tributaria y el secreto fiscal. Desafíos en México, México, UNAM, Instituto de Investigaciones Jurídicas, disponible en: http:// bibliohistorico.juridicas.unam.mx/libros/libro.htm?l=2861. 